\title{
Avaliação físico-química e organoléptica do estado de conservação de carne bovina moída, preparada industrialmente
}

\section{Physico-chemical and organoleptical evaluation of storage condition of industrially processed minced beef}

\author{
Leila Gatti Sobreiro, Elmo Rampini de Souza
}

\begin{abstract}
Resumo
Através de exames físico-químicos e organolépticos, avaliou-se o estado de conservação de carne bovina moída, preparada industrialmente e embalada a vácuo, quando mantida a temperatura de $8^{\circ} \mathrm{C}$, após a abertura da embalagem. As análises foram realizadas nos $1^{\circ}, 3^{\circ}$, $5^{\circ}$ e $7^{\circ}$ dias de armazenagem. Os resultados do $\mathrm{pH}$ mostraram que houve queda significativa $(p<0,05)$ do $1^{\circ}$ ao $7^{\circ}$ dia, passando de 5,67 a 5,51. No mesmo período, os teores de bases voláteis totais aumentaram significativamente $(p<0,05)$ de 14,99 para $19,64 \mathrm{mgN} / 100 \mathrm{~g}$. A proporção de amostras positivas para a pesquisa de amônia foi de $16,6 \%$ no $3^{\circ}$ dia, $70 \%$ no $5^{\circ}$ e $100 \%$ no $7^{\circ}$, havendo um aumento gradativo em relação ao $1^{\circ}$ dia, quando $100 \%$ das amostras apresentaram resultado negativo. Os resultados mostraram que a carne bovina moída preparada industrialmente e embalada a vácuo pode ser considerada de boa qualidade até o $3^{\circ}$ dia de armazenagem a $8^{\circ} \mathrm{C}$, justificando sua comercialização como carne resfriada.
\end{abstract}

Palavras chave: carne moída; avaliação físico-química; conservação

\section{Introdução}

Como a venda de carne fresca moída é permitida no comércio varejista, sendo obrigatória a moagem na presença do comprador (Rio de Janeiro, 1986), torna-se proibida a armazenagem do produto já cominutado. Entretanto, vem sendo notada a tendência dos estabelecimentos varejistas em comercializar carne moída com padrão de gordura pré-estabelecido, tornando-se implícita, com esta prática, a formulação de um produto.

Frente ao amplo consumo e à gama de recursos tecnológicos e higiênico-sanitários existentes na indústria contemporânea, levantou-se a hipótese de que a carne moída poderia ser preparada industrialmente, tendo um prazo de vida comercial suficiente para justificar sua comercialização como carne fresca, permanecendo acei- tável por maior período na geladeira do consumidor, sem a necessidade de ser utilizada imediatamente.

Vários trabalhos foram realizados para avaliar a qualidade da carne bovina moída. Graner et al. (1971) avaliaram a proveniente de dois tipos de estabelecimentos: açougues, onde a carne era moída na presença do consumidor e supermercados, com a carne já moída, exposta em balcão frigorificado. As amostras provenientes de açougues, e obtidas pela manhã, apresentaram os resultados mais elevados para a contagem total de mesófilos. Os citados autores atribuíram os resultados ao fato de os supermercados terem melhores condições higiênicas do que os açougues, e também porque os resíduos deixados nas máquinas moedoras permitem a multiplicação de microrganismos durante a noite, contaminando a carne comercializada na manhã seguinte.

Shoup e Oblinger (1976) compararam amostras de carne moída preparada no comércio varejista com as preparadas em uma central e posteriormente distribuídas ao comércio. Chegaram a melhores resultados microbiológicos no segundo caso, considerando importante o fato de as amostras de melhor qualidade terem sido coletadas já no varejo e não na central distribuidora onde foram preparadas.

Segundo Westhoff e Feldstein (1976) a contagem total de bactérias é maior na carne moída proveniente de mercados varejistas, devido ao maior manuseio e ao maior tempo decorrido desde o abate, do que naquela proveniente de matadouros frigoríficos ou indústrias de processamento.

Law et al. (1971) consideram que a localização do estabelecimento comercial, o nível econômico do consumidor e o grau de sua exigência determinam a qualidade da carne moída em relação à contagem total de bactérias e ao conteúdo de gordura, proteína e umidade.

Jaye et al. (1962) determinaram alguns pontos fundamentais, como a qualidade da matéria-prima utilizada e o tipo de embalagem, para que a carne moída fosse distri-

\footnotetext{
Trabalho extraído da tese apresentada pela primeira autora, sob a orientação do segundo autor, à Faculdade de Veterinária da Universidade Federal Fluminense (UFF), para obtenção do título de Mestre em Higiene Veterinária e Processamento Tecnológico de Produtos de Origem
Animal.
} 
buída mantendo suas propriedades.

Vários autores estudaram o prazo de vida comercial da carne moída embalada a vácuo (Sutherland et al., 1975; Berry e Chen, 1976; Emswiler et al., 1976; Sison et al., 1980a,b). Em todos os resultados, esse tipo de embalagem aumentou o prazo de vida comercial da carne. Hess et al. (1980) citam que este objetivo só pode ser atingido se a carne for de animal recém abatido, resfriada, desossada, cortada e/ou moída em processo ininterrupto e rápido pois, caso contrário, a flora microbiana adapta-se às diferentes fases do processamento.

Embora o sistema de empacotamento atue como fator decisivo para a manutenção da qualidade das carnes, o ponto crítico do prazo de vida útil parece residir nas condições de distribuição. A segurança e a qualidade dos alimentos são reflexos de uma interação entre produtores, industriais, distribuidores e consumidores (Institute of Food Technologists' Expert Panel on Food Safety \& Nutrition, 1981).

Objetivou-se neste trabalho: a) avaliar, através de métodos físico-químicos e organolépticos, o estado de conservação de carne bovina moída, preparada industrialmente e embalada a vácuo, quando mantida a temperatura de $8^{\circ} \mathrm{C}$, após a abertura da embalagem; b) correlacionar os resultados dos exames físico-químicos com as características organolépticas do produto, de acordo com os dias de armazenagem e c) fornecer dados para a avaliação desse produto, junto aos órgãos competentes, possibilitando que seja oferecida ao consumidor a opção de um produto de melhor qualidade, com maior prazo de vida comercial.

\section{Material e Métodos}

Foram examinadas trinta amostras provenientes de bovinos abatidos em matadouro frigorífico, sob inspeção federal, localizado no município de Presidente Prudente, Estado de São Paulo.

Após o abate, as meias-carcaças foram mantidas refrigeradas a $0 \pm 1^{\circ} \mathrm{C}$ durante $24 \mathrm{~h}$, sendo então subdivididas em quartos e em seguida desossadas em ambiente com temperatura controlada em torno de $15^{\circ} \mathrm{C}$.

Utilizou-se, nesta pesquisa, o coxão duro que foi moído e embalado a vácuo, em porções de $2 \mathrm{~kg}$, sendo cada amostra proveniente da parte muscular de um animal.

Uma vez embaladas, as amostras foram imediatamente congeladas, sendo assim mantidas no Laboratório de Controle Físico-Químico da Faculdade de Veterinária da Universidade Federal Fluminense, até o momento das análises, quando eram então descongeladas em refrigerador a $8^{\circ} \mathrm{C}$ por $48 \mathrm{~h}$. O congelamento foi um recurso utilizado para que a produção e o transporte fossem realizados de uma só vez, não sendo uma etapa proposta para a produção desse tipo de carne.
As análises foram realizadas nos $1^{\circ}, 3^{\circ}, 5^{\circ}$ e $7^{\circ}$ dias de armazenagem a $8^{\circ} \mathrm{C}$, sendo considerado $1^{\circ}$ dia aquele referente ao descongelamento e preparo.

Foram observados cor, odor e presença de limosidade, e adotados critérios próprios para o produto de acordo com as observações resultantes das alterações durante a armazenagem (Brasil, 1981).

Para a determinação do $\mathrm{pH}$ utilizou-se o método potenciométrico e avaliou-se a capacidade de reter água pelo tempo de filtração. Para a determinação do teor de bases voláteis totais (BVT) adotou-se o método de microdifusão. Utilizou-se a metodologia recomendada pelo Laboratório Nacional de Referência Animal - LANARA (Brasil, 1981). Para a pesquisa de amônia empregou-se o método colorimétrico com reativo de Nessler, citado por Bartels (1971).

Para a avaliação dos dados quantitativos de $\mathrm{pH}$ e teor de BVT, calcularam-se a média aritmética e o desvio padrão nos diversos dias de análise. Aplicou-se o teste F para verificar se as médias diárias eram estatisticamente diferentes, utilizando-se então o teste de Tuckey para estabelecer a diferença mínima significativa entre elas. A associação entre as variáveis tempo de filtração, presença de amônia e características organolépticas foi estudada através do teste não paramétrico qui quadrado $\left(\chi^{2}\right)$, observando-se sua significância nos diversos dias de estudo. Foram estabelecidas, ainda, as distribuições de freqüência para essas variáveis, através de percentuais (Vieira, 1991).

\section{Resultados e Discussão}

$1^{\circ}$ dia de armazenagem - Os valores de $\mathrm{pH}$ foram, em média, 5,67 (Fig.1). De acordo com Lawrie (1977), este $\mathrm{pH}$ favorece as enzimas que atacam os carboidratos, pois elas têm o pH ótimo entre 5,5 e 6,0, enquanto que as enzimas proteolíticas o têm em torno de 7,0 . Ginsberg e Robertson (1949) dizem que se houver degradação de carboidratos, haverá produção de ácidos.

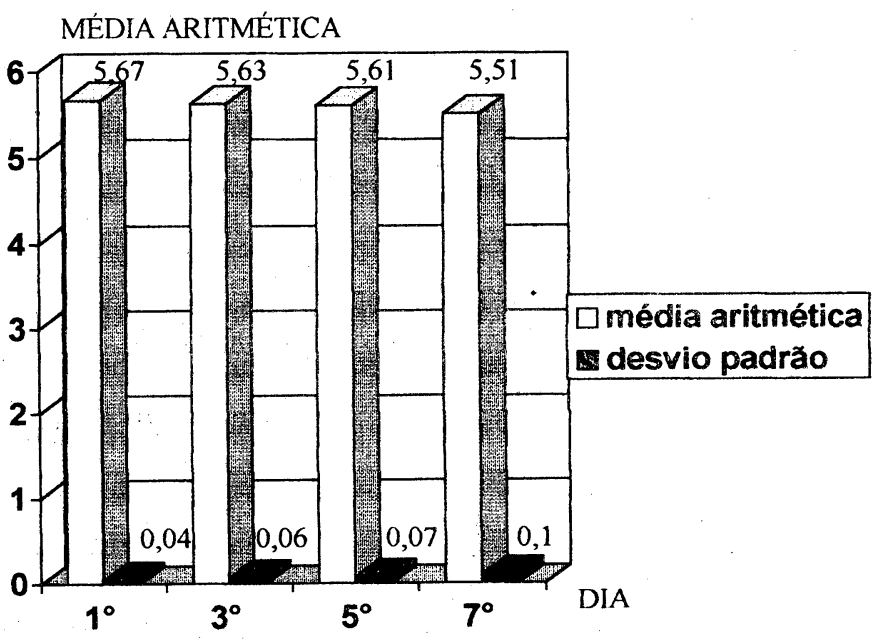

Figura 1 - Evolução dos resultados de $\mathrm{pH}$. 
O Regulamento Industrial de Inspeção Sanitária de Produtos de Origem Animal (RIISPOA) considera como carne em condições de consumo aquela com pH entre 6,0 e 6,4 (Brasil,1980) e o LANARA entre 5,8 e 6,4 (Brasil, 1981). Pode-se observar que o $\mathrm{pH}$ médio obtido no $1^{\circ}$ dia encontra-se abaixo dos limites propostos.

Na determinação de BVT, a média obtida foi de 14,99 mgN/100g (Fig. 2). Pearson (1976) e Silva (1985) consideram $13 \mathrm{mgN} / 100 \mathrm{~g}$ o limite máximo para carne fresca e $17 \mathrm{mgN} / 100 \mathrm{~g}$ para carne aceitável. No $1^{\circ} \mathrm{dia}$, a totalidade das amostras apresentou resultado negativo para a presença de amônia (Fig. 4). Considerando-se que, organolepticamente, as amostras foram classificadas como de boa qualidade, pode-se questionar o limite proposto para carne fresca, quando tratar-se de carne moída, sugerindo-se novos estudos para este produto.

Quanto ao tempo de filtração, 96,67\% das amostras liberaram o extrato aquoso em tempo menor ou igual a 5 min., enquanto $3,33 \%$ o fizeram entre 6 e $10 \mathrm{~min}$. (Fig. 3). Conseqüentemente, $96,67 \%$ foram consideradas como carne fesca e o restante como carne de média conservação, segundo os critérios do LANARA (Brasil, 1981). O resultado é concordante com Jay e Kontou (1964) que consideram que a carne fresca libera maior quantidade de extrato aquoso em menor tempo.

Não foram observadas alterações organolépticas neste dia (Figs. 5-7).

$3^{\circ}$ dia de armazenagem - Os valores de $\mathrm{pH}$ foram, em média, de 5,63, não havendo diferença significativa $(p>0,05)$ em relação aos valores obtidos no $1^{\circ}$ dia (Fig. 1). O mesmo ocorreu com o teor de BVT, cuja média foi de $15,58 \mathrm{mgN} / 100 \mathrm{~g}$ (Fig. 2).

Na pesquisa de amônia $83,33 \%$ das amostras foram negativas, enquanto que $16,67 \%$ foram positivas (Fig. 4). Gill (1983) considera que o resultado positivo para amônia confirma a deteriora da carne. Entretanto, as amostras positivas tinham características organolépticas de carne fresca e teor de BVT dentro dos limites considerados aceitáveis.

Quanto ao tempo de filtração, $90 \%$ das amostras liberaram o extrato aquoso em tempo menor ou igual a $5 \mathrm{~min}$. e $10 \%$ entre 6 e 10 min. (Fig. 3). Portanto, $90 \%$ delas tinham resultado compatível com carne fresca (Brasil, 1981).

As características organolépticas não se alteraram, sendo $100 \%$ das amostras consideradas como carne fresca (Figs. 5-7).

$5^{\circ}$ dia de armazenagem - A média obtida nos resultados de $\mathrm{pH}$ foi de 5,61 (Fig. 1). A diferença em relação ao $1^{\circ}$ dia foi estatisticamente significativa $(p<0,05)$. Desta forma, pode-se afirmar que houve queda dos valores de $\mathrm{pH}$. Os resultados estão de acordo com Jaye et al. (1962), Sutherland et al. (1975), Berry e Chen (1976), Jay e Shelef (1978), Sison et al. (1980b), Zamora e Zaritzky (1985) e Lambert et al. (1991), que consideram que a embalagem a vácuo seleciona a flora Gram positiva $(\mathrm{G}+)$ ácido-lática, que degrada carboidratos a ácido lático, diminuindo o $\mathrm{pH}$.

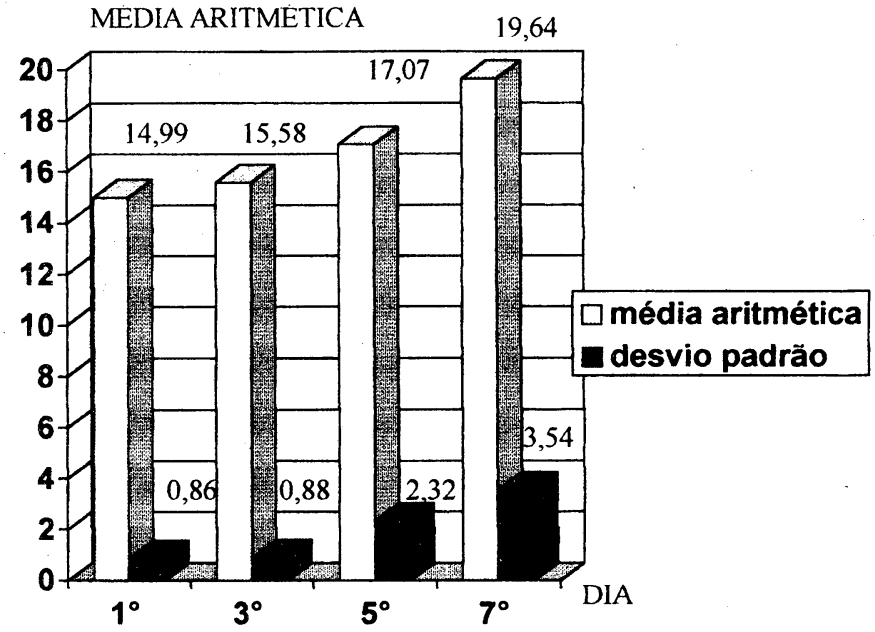

Figura 2 - Evolução dos resultados de base voláteis totais (mg $\mathrm{N} / 100 \mathrm{~g}$ ).

PERCENTUAL

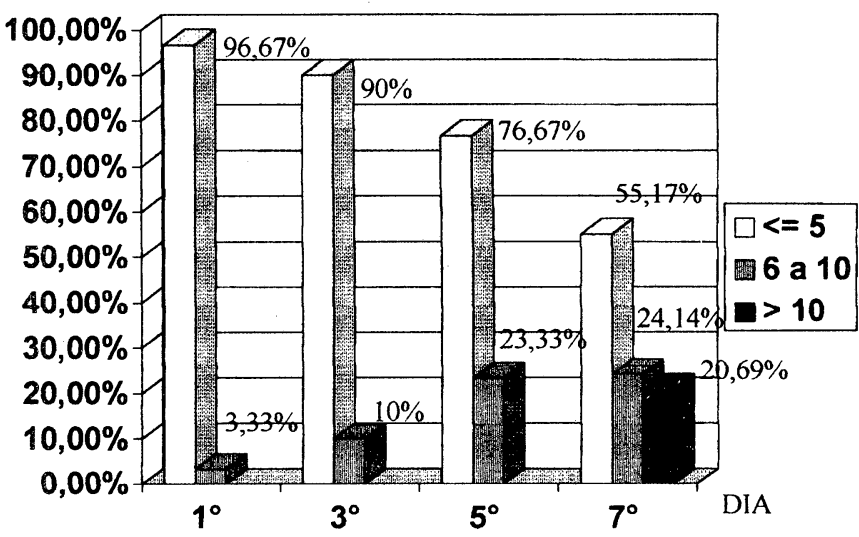

Figura 3 - Evolução dos resultados de filtração (minutos).

PERCENTUAL $100 \%$

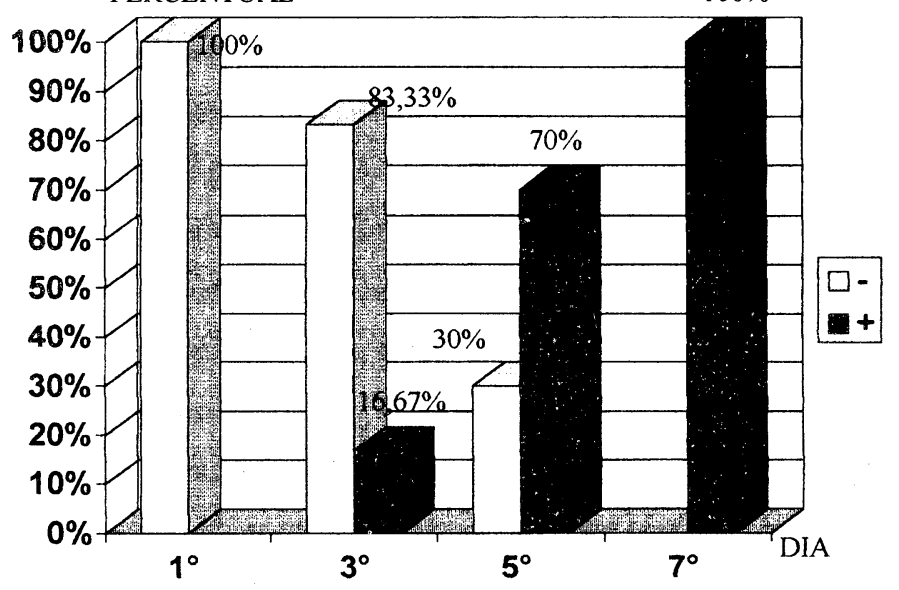

Figura 4 - Evolução dos resultados da pesquisa de amônia. 
PERCENTUAL

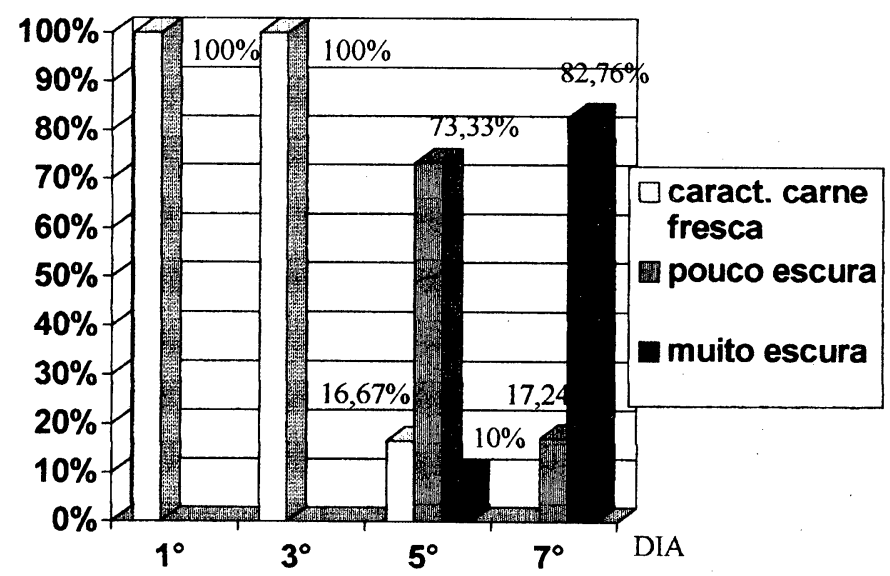

Figura 5 - Evolução da avaliação de cor.

PERCENTUAL

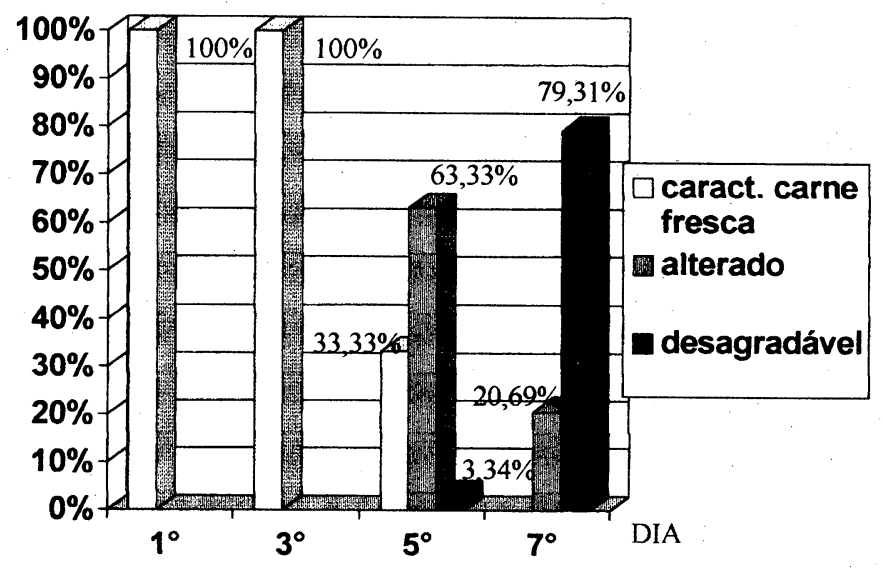

Figura 6 - Evolução da avaliação de odor.

PERCENTUAL

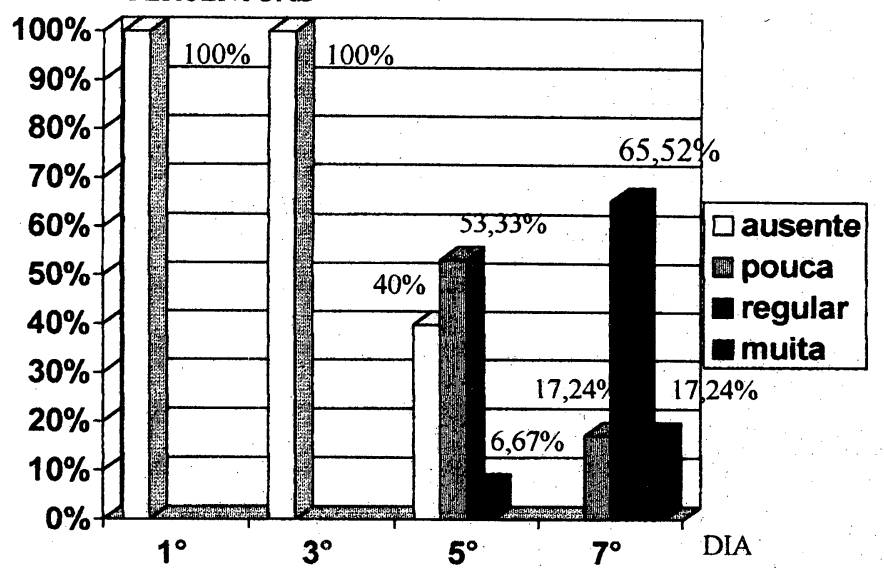

Figura 7 - Evolução da avaliação da presença de limosidade.
O teor médio de BVT foi de $17,07 \mathrm{mgN} / 100 \mathrm{~g}$, havendo diferença significativa $(p<0,05)$ em relação aos $1^{\circ}$ e $3^{\circ}$ dias de armazenagem, com aumento dos valores de acordo com este tempo (Fig. 2). A pesquisa de amônia foi positiva em $70 \%$ das amostras (Fig. 4). Comparando-se os resultados de BVT com as características organolépticas, observa-se que foi em torno do valor médio encontrado nesse dia que as amostras tiveram as primeiras alterações organolépticas, estando, portanto, de acordo com Pearson (1976) e Silva (1985), que propõem o teor de $17 \mathrm{mgN} / 100 \mathrm{~g}$ como limite aceitável para carne.

Quanto ao tempo de filtração, $76,67 \%$ das amostras liberaram o extrato aquoso em tempo menor ou igual a 5 min. e $23,33 \%$ entre 6 e $10 \mathrm{~min}$. (Fig. 3), sendo as primeiras consideradas como carne fresca e as outras como de média conservação (Brasil, 1981). Pode ser notado um aumento no tempo de filtração em relação aos $1^{\circ}$ e $3^{\circ}$ dias , estando de acordo com Jay (1964) e Jay e Kontou (1964), que citam que a carne deteriorada libera menor volume de extrato em maior tempo, devido à ação proteolítica bacteriana, que faz com que a capacidade de reter água seja maior. Shelef (1974) observou redução do volume de extrato liberado, de carne mantida a $5^{\circ} \mathrm{C}$, entre $04^{\circ}$ e $\circ 5^{\circ}$ dias de armazenagem, resultado semeIhante ao encontrado neste estudo.

Quanto à avaliação da cor, $16,67 \%$ das amostras tinham coloração de carne fresca, $73,33 \%$ alteraram-se para pouco escura e 10\% para muito escura (Fig. 5). Quanto ao odor, 33,33\% permaneceram inalteradas, $63,33 \%$ alteraram-se e 3,34\% apresentaram odor desagradável (Fig. 6). O resultado de limosidade continuou negativo em $40 \%$ das amostras, $53,33 \%$ mostraram pouca limosidade e 6,67\% tiveram resultado regular (Fig. 7). Segundo o LANARA (Brasil, 1981), as alterações organolépticas correspondem ao início de putrefação, havendo, portanto, rejeição das amostras. Kontou et al. (1966) verificaram rejeição organoléptica em carne moída no $4^{\circ}$ dia de armazenagem a $6^{\circ} \mathrm{C}$, semelhante a encontrada neste trabalho. Sison et al. (1980a) observaram odor levemente desagradável no $4^{\circ}$ dia de armazenagem da carne moída mantida a $4,4^{\circ} \mathrm{C}$ e alteração de cor e limosidade, no $6^{\circ}$ dia. Para aquela embalada a vácuo, as alterações foram notadas no $8^{\circ}$ dia (Sison et al., 1980b). Pode-se considerar que os resultados estão bem próximos dos obtidos neste trabalho, principalmente considerando-se as diferenças de temperatura de armazenagem. Deve-se considerar, também, que a carne deste experimento foi embalada a vácuo, porém, retirada da embalagem no início da armazenagem.

7 dia de armazenagem - A média dos resultados de $\mathrm{pH}$ foi de 5,51 (Fig. 1). Houve diferença significativa $(p<0,05)$ em relação a todas as médias anteriores, confirmando mais uma vez a queda dos valores de $\mathrm{pH}$.

Quanto ao teor de BVT, a média foi de $19,64 \mathrm{mgN} /$ $100 \mathrm{~g}$, havendo diferença significativa $(p<0,05)$ em relação aos dias anteriores (Fig. 2). Os resultados estão de 
acordo com Pearson (1976) e Silva (1985), que consideram rejeitada a carne com valores acima de $17 \mathrm{mgN} / 100 \mathrm{~g}$. Os resultados da pesquisa de amônia foram $100 \%$ positivos (Fig. 4).

Houve aumento do tempo de filtração em relação ao $5^{\circ}$ dia, com $55,17 \%$ das amostras liberando o extrato aquoso em tempo menor ou igual a 5 min., $24,14 \%$ entre 6 e 10 min. e 20,69\% em tempo superior a 10 min. (Fig. 3). Portanto, de acordo com os critérios de julgamento adotados nesta prova (Brasil, 1981), 20,69\% das amostras estariam classificadas como carne suspeita, provavelmente alterada. Não houve correlação estatística com as outras variáveis no $5^{\circ}$ e no $7^{\circ}$ dia. Levando-se em conta que as primeiras 14 amostras permaneceram congeladas por, no máximo, 50 dias, enquanto que as outras assim permaneceram de 64 a 117 dias, pode-se supor que o tempo de congelamento alterou a capacidade de reter água deste último grupo. Laszlo et al. (1986) citam que o congelamento é uma das causas da desnaturação protéica, modificando suas estruturas secundárias, terciárias e quaternárias, e interferindo na capacidade de reter água. Concordam Brewer e Harbers (1991), concluindo que a capacidade de reter água diminui com o aumento do tempo de estocagem sob congelamento, independente da embalagem utilizada, devido à desnaturação protéica, à formação de produtos de auto-oxidação e à formação de cristais de gelo.

Em relação à cor, nenhuma das amostras permaneceu com características de carne fresca; o percentual de pouco escura foi reduzido de $73,33 \%$ a $17,24 \%$ e o de muito escura aumentado de $10 \%$ para $82,76 \%$ (Fig. 5). Assim como a cor, não houve odor característico de carne fresca, reduzindo-se o percentual de alterado de $63,33 \%$ para $20,69 \%$ e elevando-se o de desagradável de $3,34 \%$ para $79,31 \%$ (Fig. 6). Não foi observada ausência de limosidade, tendo $17,24 \%$ das amostras pouca limosidade, 65,52\% regular e 17,24\% muita (Fig. 7). O grau de correlação destas variáveis foi alto $(p<0,01)$. Portanto, a totalidade das amostras foi rejeitada organolepticamente no $7^{\circ}$ dia de armazenagem, correspondendo ao teor de BVT de 19,64 mgN/100g.

Alguns autores estudaram o prazo de vida útil da carne bovina moída. Berry e Chen (1976) verificaram que ela permaneceu aceitável por 3 dias a $2^{\circ} \mathrm{C}$, após ter permanecido de 0 a 12 dias embalada a vácuo, à mesma temperatura. Emswiler et al. (1976) obtiveram carne moída de boa qualidade por 18 dias, quando embalada a vácuo e mantida em torno de $-1,7^{\circ} \mathrm{C}$. Raccach e Henrickson (1978) estipularam 5 dias de vida útil para aquela mantida em torno de $5^{\circ} \mathrm{C}$, não embalada a vácuo. Sison et al. (1980a,b) determinaram prazo de vida útil de 5 dias para a não embalada a vácuo e de 7 dias para a carne embalada a vácuo, ambas mantidas a $4,4^{\circ} \mathrm{C}$. Zamora e Zaritzky (1985) sugerem 8 dias de prazo para carne moída em embalagem permeável e 14 dias para a embalada a vácuo, quando mantidas a $4^{\circ} \mathrm{C}$. Torna-se difícil a comparação entre os autores, devi- do às diferentes temperaturas utilizadas. O mesmo ocorre no presente trabalho, em que utilizaram-se $8^{\circ} \mathrm{C}$, por ser considerada a temperatura atingida pelos refrigeradores domésticos mais próxima da realidade. Segundo Judge et al. (1989), a carne bovina deve ser consumida num prazo máximo de 4 dias após a compra, quando mantida entre 3 e $5^{\circ} \mathrm{C}$ na geladeira do consumidor. Este prazo está próximo dos resultados obtidos neste trabalho, em que a carne moída permaneceu própria ao consumo por 3 dias, a $8^{\circ} \mathrm{C}$.

Os resultados obtidos, semelhantes à carne bovina em cortes de açougue, podem ser atribuídos ao processo ininterrupto de obtenção e preparo da carne, considerado fundamental por Hess et al. (1980), além da matéria-prima de boa qualidade, indispensável para a carne moída embalada a vácuo (Jaye et al., 1962).

\section{Conclusões}

Considerando-se os resultados obtidos nesta pesquisa, pode-se concluir que: 1) a carne bovina pode ser comercializada moída, frigorificada, desde que preparada industrialmente, em processo ininterrupto e embalada a vácuo; 2) quando armazenada a $8^{\circ} \mathrm{C}$, pode ser considerada própria para o consumo por 3 dias, uma vez aberta a embalagem; 3) devido à queda do $\mathrm{pH}$, este critério não deve ser considerado isoladamente na avaliação do estado de conservação desse produto, pois foge dos parâmetros normalmente utilizados para carne fresca; 4) a avaliação do tempo de filtração não deve ser utilizada se esta carne for congelada, pois há alterações em seus resultados; 5) uma vez que a degradação protéica pode ser avaliada pela determinação de bases voláteis totais, esta prova foi considerada mais eficaz do que a pesquisa de amônia, já que, sendo a primeira quantitativa, pode-se ter uma melhor idéia da evolução do processo de deterioração da carne; e 6) a observação das características organolépticas é de grande valia para a carne moída, principalmente quando comparadas ao teor de BVT.

\section{Abstract
Physico-chemical and organoleptical evaluation of storage condition of industrially processed minced beef

Storage condition of minced beef industrially processed and vacuum packed was evaluated through physicochemical and organoleptical analysis. The tests were performed on the $1^{\text {st }}, 3^{\text {rd }}, 5^{\text {th }}$ and $7^{\text {th }}$ days of storage at $8^{\circ} \mathrm{C}$, after package opening. A significant decrease $(p<0.05)$ was found in $\mathrm{pH}$ value from 5.67 in the $1^{\text {st }}$ day to 5.51 in the $7^{\text {th }}$ day. The total volatile bases increased significantly $(p<0.05)$ from 14.99 to $19.64 \mathrm{mgN} / 100 \mathrm{~g}$ in the same period. The percentages of ammonium in positive samples were $16.6 \%$ in the $3^{\text {rd }}$ day, $70 \%$ in the $5^{\text {th }}$ day and $100 \%$ in the $7^{\text {th }}$ day. In the $1^{\text {st }}$ day no sample gave positive results. From this results, it can be concluded that minced beef may be considered of good quality up to the $3^{\text {rd }}$ day of 
storage at $8^{\circ} \mathrm{C}$, if industrially processed and vacuum packed and, in this way, be commercialized as fresh refrigerated meat.

Key words: minced beef; physico-chemical evaluation; storage

\section{Referências bibliográficas}

BARTELS, H. Inspeccion Veterinária de la Carne. Zaragoza. Acribia, 1971. $491 \mathrm{p}$.

BERRY, B.W. , CHEN, A.A. Bacterial, shelf life and consumer acceptance characteristics of chopped beef. J. Milk Food Technol., v. 39, n. 6, p. 405-407, 1976.

BRASIL. MINISTÉRIO DA AGRICULTURA E REFORMA AGRÁRIA. Decreto $n^{\circ} 30.691$, de 29 de março de 1952. Aprova o novo Regulamento de Inspeção Industrial e Sanitária de Produtos de Origem Animal. Brasília, 1980. 166 p.

BRASIL. MINISTÉRIO DA AGRICULTURA E REFORMA AGRÁRIA. LABORATÓRIO NACIONAL DE REFERÊNCIA ANIMAL. Métodos Analíticos Oficiais para Controle de Produtos de Origem Animal e seus Ingredientes. Brasília, 1981. 81 p. v. 2. Métodos Físico-Químicos.

BREWER, M.S. , HARBERS, C.A.Z. Effect of the packaging on physical and sensory characteristics of ground pork in longterm frozen storage. J. Food Science, v. 56, n. 3, p. 627631, 1991.

EMSWILER, B.S.; PIERSON, C.J., KOTULA, A.W. Bacteriological quality and shelf life of ground beef. Applied Environm. Microbiol., v. 31, p. 826-830, 1976.

GILL; C.O. Meat spoilage and evaluation of the potential storage life of fresh meat. J. Food Protection, v. 46, n. 5, p. 444-452, 1983.

GINSBERG, A. , ROBERTSON, A. The examination of minced meat. Vet. Record, v. 61, n. 35, p. 540-543, 1949.

GRANER, M., MARTINELLI FILHO, A., CRUZ, V.F. Microbiologia da carne moída: 1. Contagem total de bactérias. Anais da Escola Superior de Agricultura "Luiz de Queiroz", v. 28, p. 217-226, 1971.

HESS, E, RUOSCH, W. , BREER, C. Extending the shelf-life of prepacked fresh meat. Fleischwirtschaft, v. 60, n. 8, p. 15131517, 1980.

INSTITUTE OF FOOD TECHNOLOGISTS' EXPERT PANEL ON FOOD SAFETY \& NUTRITION. Open shelf-life dating of food. Food Technol., p. 89-96, 1981.

JAY, J.M. Release of aqueous extracts by beef homogenates and factors affecting release volume. Food Technol., p. 129132, 1964.

JAY, J.M., KONTOU, K.S. Evaluation of the extract-release volume phenomenon as a rapid test for detecting spoilage in beef. Applied Microbiol., v. 12, n. 4, p. 378-383, 1964.

JAY, J.M., SHELEF, L.A. Microbial modifications in raw and processed meats and poultry at low temperatures. Food Technol, p. 186-187, 1978.

JAYE, M. , KITTAKA, R.S. , ORDAL, Z.J. The effect of temperature and packaging material on the storage life and bacterial flora of ground beef. Food Technol., p. 95-98, 1962.

JUDGE, M., ABERLE, E., FORREST, J. Principles of Meat Science, 2 ed. , lowa: Kendall/Hunt 1989. 351 p. Cap. 9: Storage and preservation of meat, p. 203-224.
KONTOU, K.S., HUYCK, M.C., JAY, J.M. Relationship between sensory test scores, bacterial numbers and ERV on pairedraw and cooked ground beef from freshness to spoilage. Food Technol., p.128-131, 1966.

LAMBERT, A.D., SMITH, J.P. , DODDS, K.L. Shelf life extension and microbiological safety of fresh meat - A Review. Food Microbiol., v. 8, p. 267-297, 1991.

LASZLO, H., BASSO, L.M., COELHO, C.M.L. Química de Alimentos e Alterações dos Componentes Orgânicos. São Paulo. Nobel, 1986. 98p. Cap. 2: Protídeos, p. 32-43.

LAW, H.M., YANG, S.P., MULLINS, A.M. Ground beef quality at the retail level. J. American Dietetic Association, v. 58, p. 230-233, 1971.

LAWRIE, R.A. Ciência de La Carne. 2. ed. Zaragoza. Acribia, 1977. $456 \mathrm{p}$.

PEARSON, D. Técnicas de Laboratório para el Análises de Alimentos. Zaragoza. Acribia, 1976. 331 p. Cap. 7: Alimentos cárnicos - Carne y pescado, p. 179-225.

RACCACH, M., HENRICKSON, R.L. Storage stability and bacteriological profile of refrigerated ground beef from electrically-stimulated hot-boned carcasses. J. Food Protection, v. 41, n. 12, p. 957-960, 1978.

RIO DE JANEIRO. SECRETARIA MUNICIPAL DE SAÚDE. Decreto n. 6235, de 30 Out. 1986. Aprova o Regulamento da Defesa e Proteção da Saúde no Tocante a Alimentos e à Higiene Habitacional e Ambiental. Diário Oficial (do Estado do Rio de Janeiro) - Municipalidades, Rio de Janeiro, 03 Nov. 1986.

SHELEF, L. A. Hydratation and $\mathrm{pH}$ of microbially spoiling beef. J. Applied Bacteriol., v. 37, p. 531-536, 1974.

SHOUP, J.G., OBLINGER, J.L. Microbiological evaluation of retail ground beef: Centralized and traditional preparation. J. Milk Food Technol., v. 39, n. 3, p. 179-183, 1976.

SILVA, A. M. Avaliação do Estado de Conservação de Carne Bovina a Nível de Consumo. Niterói, 1985. 110 p. Dissertação (Mestrado em Medicina Veterinária) - Universidade Federal Fluminense.

SISON, E. C. , MATA, M.L. , BALDONADO, E.M. , OLAGUER, I.L. , GONZALES, R.R. , PIMENTEL, L.A. , BEZA, C.G. Microbiological, chemical and sensory quality changes in fresh meat: I. Beef stored at four temperatures. Philippine Agriculturist, v. 63, p. 28-37, 1980a.

SISON, E C. , MATA, M.L., BALDONADO, E.M. , OLAGUER, I.L. , GONZALES, R.R., PIMENTEL, L.A. , BEZA, C.G. Microbiological, chemical and sensory quality changes in fresh meat: IV. Vacuum-packaged beef stored at refrigeration and lunctuating temperatures. Philippine Agriculturist, v. 63, p. 61-66, $1980 \mathrm{~b}$.

SUTHERLAND, J.P., PATTERSON, J.T. , MURRAY, J.G. Changes in the microbiology of vacuum-packaged beef. $J$. Applied Bacteriol, v. 39, p. 227-237, 1975.

VIEIRA, S. Introdução à Bioestatística. 2.ed. Rio de Janeiro. Campus, 1991. 203 p.

WESTHOFF, D., FELDSTEIN, F. Bacteriological analysis of ground beef. J. Milk Food Technol., v. 39, n. 6, p. 401-404, 1976.

ZAMORA, M.C. , ZARITZKY, N.E. Modeling of microbial growth in refrigerated packaged beef. J. Food Science, v. 50, p. 1003-1006, 1985. 